\title{
Anxiety and Depression as Risk Factors in Frontotemporal Dementia and Alzheimer's Disease: The HUNT Study
}

\author{
Hege Rasmussen ${ }^{a, b} \quad$ Tor Atle Rosness $^{c} \quad$ Ole Bosnes $^{a} \quad \varnothing$ Øyvind Salvesen ${ }^{d}$ \\ Marlen Knutlie $^{\mathrm{e}}$ Eystein Stordal ${ }^{\mathrm{a}, \mathrm{b}}$ \\ a Namsos Hospital, Clinic for Mental Health and Substance Abuse, Nord-Trøndelag Hospital \\ Trust (HNT), Namsos, Norway; ${ }^{b}$ Department of Mental Health, Norwegian University of \\ Science and Technology (NTNU), Trondheim, Norway; ${ }^{\mathrm{C}}$ The Faculty of Mathematics and \\ Natural Sciences, School of Pharmacy, University of Oslo, Oslo, Norway; ${ }^{d}$ Department \\ of Public Health and General Practice, Norwegian University of Science and Technology

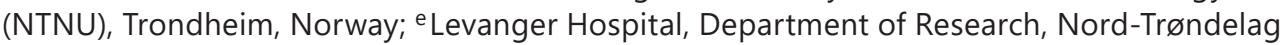 \\ Hospital Trust (HNT), Levanger, Norway
}

\section{Keywords}

Longitudinal studies - Case-control studies - Dementia - Frontal lobe $\cdot$ Neurodegenerative diseases · Epidemiology · Psychiatric symptoms

\section{Abstract}

Background: The roles of both anxiety and depression as risk factors for frontotemporal dementia (FTD) and Alzheimer's disease (AD) have not been previously investigated together. Objective: To study anxiety and depression as independent risk factors for FTD and AD. Methods: Eighty-four patients with FTD and 556 patients with AD were compared with 117 cognitively healthy $(\mathrm{CH})$, elderly individuals. Both cases and controls were participants in the second Health Study of Nord-Trøndelag (HUNT2) from 1995 to 1997, in which depression and anxiety were assessed with the Hospital Anxiety and Depression Scale (HADS). Results: Significant associations were found between anxiety and FTD and between depression and AD. A significantly increased risk of developing FTD was observed in patients who had reported anxiety on the HADS ( $p=0.017$ ) (odds ratio [OR]: $2.947,95 \%$ confidence interval [CI]: 1.209-7.158) and a significantly increased risk of developing $A D$ was observed in patients who had reported depression on the HADS ( $p=0.016)$ (OR: 4.389, 95\% Cl: 1.311-14.690). Conclusion: Our study findings suggest that anxiety and depression may play different roles as risk factors for FTD and $A D$. 


\section{Background}

The number of individuals with dementia worldwide is estimated to be over 45 million and is predicted to triple by 2050 [1]. The identification of modifiable risk factors may lead to viable prevention strategies [2]. Frontotemporal dementia (FTD) refers to clinical syndromes caused by neurodegeneration in the frontal or temporal lobes of the brain. FTD consists of three clinical subtypes: (1) behavioral variant FTD (bvFTD), which is characterized by changes in personality and behavior; (2) non-fluent variant primary progressive aphasia, which is characterized by deficits in speech and grammar, and (3) semantic variant primary progressive aphasia, which is characterized by deficits in semantic knowledge and naming $[3,4]$.

FTD accounts for $10 \%$ of all occurring dementia cases and is a leading cause of earlyonset dementia, i.e., onset before the age of 65 years. Early symptoms often include insidious behavioral and personality changes and problems with language $[5,6]$. The symptoms of behavioral and personality changes are similar to symptoms seen in psychiatric disorders and this often leads to an incorrect initial diagnosis [7]. About $60 \%$ of FTD cases are diagnosed between the age of 45 and 60 years $[8,9]$. Modifiable risk factors in FTD have been investigated far less than in Alzheimer's disease (AD) and vascular dementia and although some studies have found associations between FTD and diabetes mellitus [10], head trauma [11-13], education level [14], and autoimmune disease [15], knowledge on modifiable risk factors in FTD is considered sparse [16].

$\mathrm{AD}$ accounts for $60-80 \%$ of all cases of dementia [17], and these patients display early symptoms of memory problems, apathy, as well as depression, and later communication problems, confusion, disorientation, behavioral changes, and difficulties with speech, swallowing, and walking [8]. Several risk factors for AD have been researched and established, including hypertension, diabetes, hypercholesterolemia, body mass index (BMI), education, and socioeconomic status, along with depression, affective disorders, social network, and social engagement [18-22].

Anxiety and depression are common mental disorders among the general population [23, 24]. Symptoms of depression and anxiety are graded by their severity, duration, and functional impairment, and a diagnosis of anxiety or depression requires a clinical assessment [25]. Depression is a common disorder in the elderly population, and studies performed in the last decade have implied an increasing prevalence of depression with age [26, 27]. Anxiety is harder to assess in elderly individuals, but studies have found it to occur less often than depression and that severe forms are also less common in the elderly [28].

A few studies have compared risk factors in FTD and AD, finding that patients with FTD were less likely to have hypertension [14, 29], had a lower prevalence of cerebrovascular risk factors [29], were younger and more educated, and were more likely to have a positive family history of dementia than patients with $\mathrm{AD}$ [14]. Not only is knowledge of modifiable risk factors for FTD sparse, there has also been a lack of longitudinal studies assessing modifiable risk factors and their impact on premorbid FTD and AD. The aim of this longitudinal population-based case-control study was to investigate the role of anxiety and depression as modifiable risk factors in FTD compared with in AD.

\section{Methods}

\section{Study Population}

In this population-based, longitudinal nested case-control study, the study population comprised of 84 individuals with FTD, 556 individuals with AD, and a control group of 117 


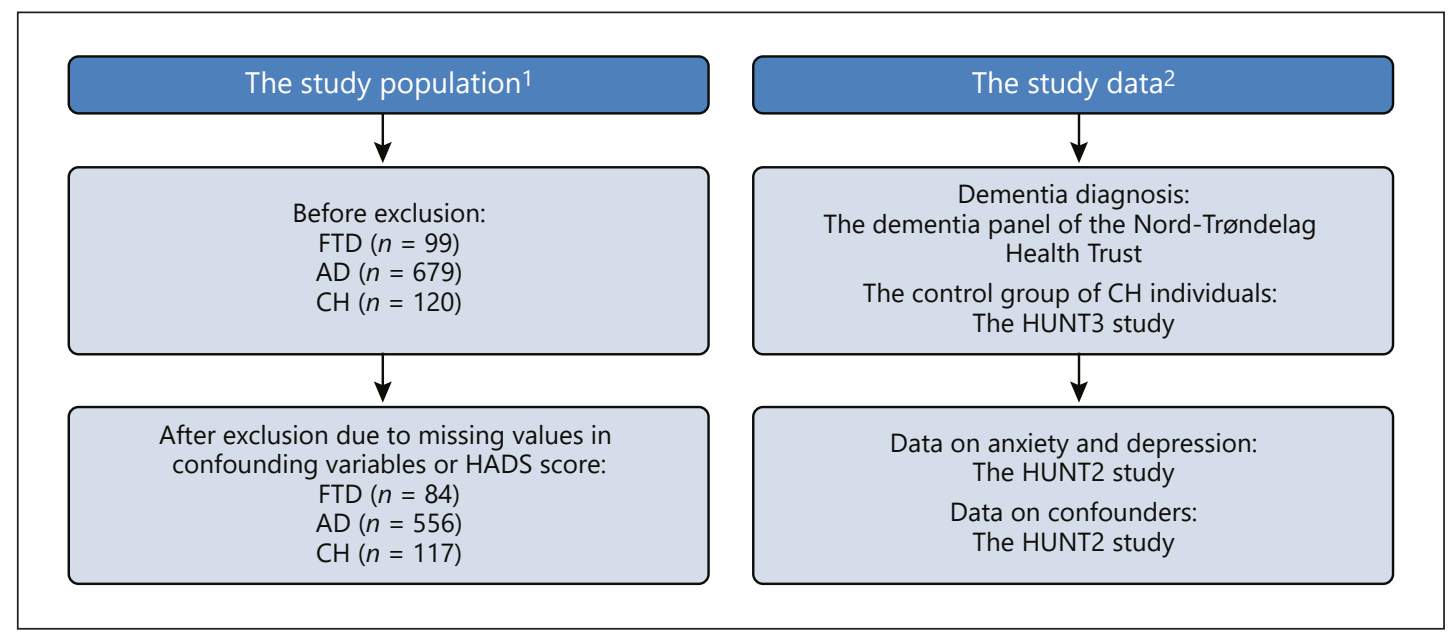

Fig. 1. Study population and data. ${ }^{1}$ Study population before and after exclusion. ${ }^{2}$ Study data: dementia diagnosis, assessments of anxiety and depression, and confounders. FTD, frontotemporal dementia; AD, Alzheimer's disease; $\mathrm{CH}$, cognitively healthy.

verified cognitively healthy $(\mathrm{CH})$ elderly individuals (Fig. 1). Cases with a diagnosis of FTD and AD were identified from the Dementia Register of the Nord-Trøndelag Hospital Trust [30] (Fig. 1). This Dementia Register consists of data collected from a Nursing Home Dementia Register and a Hospital Dementia Register.

The $\mathrm{CH}$ control group was selected from a follow-up project on memory and intelligence after HUNT3 between 2010 and 2011 [31] (Fig. 1). During this project, the individuals were examined by a neuropsychologist and categorized as $\mathrm{CH}$ [31].

All cases and controls in our study had participated in the second study of the Health Study of Nord-Trøndelag (HUNT2) between 1995 and 1997 and completed the Hospital Anxiety and Depression Scale (HADS). In the HUNT2 study, participants underwent a brief medical examination and were asked to complete questionnaires including physical and mental health-related items. The HUNT2 study has been described in more detail previously [32].

FTD and AD cases and CH individuals with valid HADS scores were included in our study. Cases and controls with missing data or nonvalid HADS scores were excluded (Fig. 1).

\section{Dementia Diagnosis}

The Hospital Dementia Register includes data on dementia diagnosis collected retrospectively (1995-2010) and prospectively (2010-2017) by the Nord-Trøndelag Hospital Trust. Diagnosis is performed according to national and international guidelines by specialists in geriatric and psychogeriatric medicine, and is based on patient history, caregiver history, clinical examinations, neuropsychological assessments, blood samples, and brain imaging [30].

The Nursing Home Dementia Register includes data on dementia diagnosis collected from nursing homes in Nord-Trøndelag during 2010-2011. Diagnostic data were collected by trained nurses by conducting several tests measuring cognitive function, neuropsychiatric symptoms, depression symptoms, quality of life, caregiver distress, and personal activities of daily living. Using the available information, two physicians with wide clinical and research experience independently diagnosed mild cognitive impairment, dementia syndromes, and dementia subtypes. If there was any discrepancy, a third expert was consulted [30]. 


\section{Anxiety and Depression Measurements}

Data on self-reported symptoms of anxiety and depression were extracted from the HUNT2 study, in which the HADS was used to measure depression and anxiety (Fig. 1). The HADS consists of 14 items covering 2 subscales, with 7 items for anxiety (HADS-A) and 7 for depression (HADS-D). Each item is scored on a 4-point Likert scale (0: not present, 3: fully present). The subscale sum scores have a minimum of 0 and maximum of 21. Snaith and Zigmond [33] categorized the HADS-A and HADS-D subscale scores of 0-7 as normal, 8-10 as mild disorder, 11-14 as moderate disorder, and 15-21 as severe disorder. In this study, we included HADS scores where at least five out of the seven questions on both HADS-D and HADS-A were answered. Those who filled in 5 or 6 items were included and their score was based on the sum of completed items multiplied with 7 of 5 or 7 of 6 .

In the FTD group, 3 cases had answered 5 out of 7 items and 13 cases had answered 6 out of 7 items on the HADS-A. No cases had answered 5 out of 7 items and 5 cases had answered 6 out of 7 items on the HADS-D. In the AD group, 34 cases had answered 5 out of 7 items and 97 cases had answered 6 out of 7 items on the HADS-A. Sixteen cases had answered 5 out of 7 items and 64 cases had answered 6 out of 7 items on the HADS-D. In the CH group, 7 controls had answered 5 out of 7 items and 18 controls had answered 6 out of 7 items on the HADS-A. One control had answered 5 out of 7 items and 7 controls had answered 6 out of 7 items on the HADS-D. We used a score of 8 or above as the cutoff indicating a probable case of anxiety or depression [34].

\section{Confounders}

Data on confounders were extracted from the HUNT2 study. Based on previous studies, we selected variables that might confound the associations between anxiety/depression and FTD/AD. Confounders can influence both the dependent variable and the independent variable, causing a spurious association. Therefore, the confounders chosen for this study were gender, age at participation in the HUNT2 study, heart disease, diabetes, metabolic disorder, hypertension, smoking, and obesity. Heart disease was ascertained if participants indicated they had experienced angina pectoris or heart attack. Similarly, diabetes and metabolic disorders (hypothyroidism or hyperthyroidism) were determined if responses were positive. Hypertension was determined if participants had an average diastolic blood pressure of $90 \mathrm{~mm} \mathrm{Hg}$ or more. Patients with a BMI of 30 or higher were classified as obese. Tobacco use was categorized as never smoked on a daily basis, previous daily smoker, or daily smoker. Owing to missing data, potential confounders, such as education, brain disease, and alcohol use, were not included in the final analysis.

\section{Statistical Analysis}

Datasets from the Dementia Register of the Nord-Trøndelag Hospital Trust and the HUNT2 study were merged using the personal identification number assigned to all Norwegian citizens. The personal identification number was then replaced with an anonymous project identification number before the merged dataset was made available to the researchers. We evaluated the association between anxiety and depression, measured by HADS in the HUNT2 study, and the later development of FTD and AD using multivariable logistic regression. Three analyses were performed separately: (1) analysis of FTD versus CH individuals; (2) analysis of FTD versus AD; and (3) analysis of AD versus $\mathrm{CH}$ individuals. All three analyses were performed in four steps: (1) entering anxiety only as the variable; (2) entering depression only as the variable; (3) entering anxiety and depression as variables; and (4) entering anxiety and depression as variables and adjusting for the potential confounders of age, gender, heart disease, diabetes, hypertension, metabolic disease, smoking, and obesity. The analyses were performed using SPSS version 25. 
Table 1. Characteristics of the study population

\begin{tabular}{llll}
\hline & $\begin{array}{l}\text { FTD } \\
(n=84)\end{array}$ & $\begin{array}{l}\text { AD } \\
(n=556)\end{array}$ & $\begin{array}{l}\text { CH } \\
(n=117)\end{array}$ \\
\hline $\begin{array}{l}\text { Female, \% } \\
\text { Mean age at participation in the HUNT2 study, years }\end{array}$ & 66.7 & 68.7 & 53.0 \\
Mean age at dementia diagnosis, years & 67.7 & 71.8 & 61.2 \\
Risk factors, \% & 74.4 & 79.2 & \\
$\quad$ Heart disease & 15.5 & 16.0 & 6.8 \\
$\quad$ Diabetes & 3.6 & 5.0 & 1.7 \\
Hypertension & 32.1 & 29.5 & 29.9 \\
Metabolic disease & 11.9 & 8.3 & 6.0 \\
Smoking & 53.5 & 44.9 & 57.2 \\
Obesity & 26.2 & 18.0 & 12.8 \\
Anxiety & 29.3 & 21.1 & 8.8 \\
Depression & 13.0 & 13.9 & 2.7 \\
\hline
\end{tabular}

The study was conducted at the Namsos Hospital, Nord-Trøndelag Health Trust, with approval from the Regional Etisk Komite (REK), the Norwegian ethics committee. Participating patients gave written consent to take part in the HUNT2 and HUNT3 studies [35].

\section{Results}

\section{Characteristics of the Study Population}

Compared with the $\mathrm{CH}$ group, the $\mathrm{AD}$ and FTD groups were older at participation in the HUNT2 study and were more likely to have heart disease, diabetes, metabolic disease, obesity, anxiety, and depression. Compared with the AD group, the FTD group was younger at participation in the HUNT2 study and at time of diagnosis. The FTD cases were also more likely to have hypertension, metabolic disease, obesity, as well as anxiety and to smoke (Table 1). All cases in the FTD group received their dementia diagnosis after the year 2000. In the AD group, 26 cases received their dementia diagnosis between 1995 and 1999 and the remainder after the year 2000 .

\section{FTD Compared to CH Individuals}

In the initial analysis entering only anxiety as a variable, a significant association between anxiety and developing FTD was seen ( $p=0.000$; odds ratio [OR]: 4.303, 95\% confidence interval [CI]: 1.925-9.622) compared with the $\mathrm{CH}$ group. When entering only depression as a variable, a significant association between depression and developing FTD was also seen ( $p=0.012$; OR: 5.473, 95\% CI: 1.454-20.599). When both anxiety and depression were entered as variables, a significant increase in the risk of developing FTD was observed in patients who had reported anxiety on the HADS ( $p=0.017$; OR: 2.947, 95\% CI: 1.209-7.158). There was no significant association between depression and risk of developing FTD ( $p=0.151$; OR: 2.879 , 95\% CI: 0.681-12.176). The findings regarding anxiety were consistent after adjusting for the potential confounders ( $p=0.045$; OR: $2.797,95 \%$ CI: 1.024-7.642) (Table 2).

\section{FTD Compared to $A D$}

In the initial analysis entering only anxiety as a variable, no significant association between anxiety and developing FTD was seen ( $p=0.099$; OR: 1.549, 95\% CI: 0.920-2.607) compared with the AD group. When entering only depression as a variable, no significant 
Table 2. Comparison between FTD and CH groups

\begin{tabular}{|c|c|c|c|c|}
\hline & $p$ value & OR & $\begin{array}{l}\text { Lower } \\
(95 \% \mathrm{CI})\end{array}$ & $\begin{array}{l}\text { Upper } \\
(95 \% \text { CI) }\end{array}$ \\
\hline Anxiety $^{\mathrm{a}}$ & 0.000 & 4.303 & 1.925 & 9.622 \\
\hline Depression $^{\mathrm{b}}$ & 0.012 & 5.473 & 1.454 & 20.599 \\
\hline Anxiety and & 0.017 & 2.942 & 1.209 & 7.158 \\
\hline depression $^{c}$ & 0.151 & 2.879 & 0.681 & 12.176 \\
\hline \multicolumn{5}{|l|}{ Adjusted analysis ${ }^{\mathrm{d}}$} \\
\hline Anxiety & 0.045 & 2.797 & 1.024 & 7.642 \\
\hline Depression & 0.100 & 3.925 & 0.771 & 19.982 \\
\hline Age at participation in HUNT2 & 0.000 & 1.095 & 1.049 & 1.143 \\
\hline Gender & 0.243 & 0.651 & 0.316 & 1.339 \\
\hline Heart disease & 0.076 & 2.716 & 0.902 & 8.175 \\
\hline Diabetes & 0.745 & 0.687 & 0.071 & 6.611 \\
\hline Hypertension & 0.876 & 1.060 & 0.511 & 2.196 \\
\hline Metabolic disease & 0.484 & 0.929 & 0.756 & 1.142 \\
\hline Smoking & 0.080 & 1.525 & 0.950 & 2.447 \\
\hline Obesity & 0.027 & 2.648 & 1.119 & 6.268 \\
\hline
\end{tabular}

Anxiety and depression as risk factors for FTD compared with $\mathrm{CH}$ individuals. $\mathrm{CI}$, Confidence interval; OR, odds ratio. a Anxiety entered as variable. ${ }^{\mathrm{b}}$ Depression entered as variable. ${ }^{\mathrm{c}}$ Anxiety and depression entered as variables. ${ }^{\mathrm{d}}$ Anxiety, depression, and confounders entered as variables.

association between depression and developing FTD was seen ( $p=0.828$; OR: $0.924,95 \%$ CI: $0.453-1.883$ ) compared with the AD group. When both anxiety and depression were entered as variables, there were no significant associations between anxiety and developing FTD ( $p=$ 0.146; OR: 1.592, 95\% CI: 0.851-2.979) or between depression and developing FTD ( $p=$ 0.490; OR: 0.751, 95\% CI: 0.333-1.694) compared with AD. No significant associations for anxiety or depression were seen after adjusting for potential confounders (Table 3).

\section{AD Compared to CH Elderly}

In the initial analysis entering only anxiety as a variable, a significant association for developing AD was seen ( $p=0.003$; OR: 2.778, 95\% CI: 1.404-5.498). When entering only depression as a variable, a significant association for developing AD was also seen $(p=0.003$; OR: 5.922, 95\% CI: 1.829-19.181). When both anxiety and depression were entered as variables, a nearly significant increase in the risk of developing AD was observed in patients who had reported anxiety on the HADS ( $p=0.054$; OR: 2.009, 95\% CI: 0.988-4.087). There was also a significant association between depression and the risk of developing $\operatorname{AD}(p=0.016$; OR: $4.389,95 \%$ CI: 1.311-14.690). The nearly significant association for anxiety was reduced ( $p=0.114$; OR: 1.967, 95\% CI: 0.850-4.554) after adjusting for potential confounders. The findings regarding depression were consistent after adjusting for potential confounders ( $p=$ 0.032; OR: 4.494, 95\% CI: 1.139-17.731) (Table 4).

\section{Discussion}

This study investigated the association between anxiety and depression and the risk of receiving a diagnosis of FTD or AD. Anxiety was more likely to be reported at baseline in the HUNT2 study among those who later developed FTD than in the CH control group. Conversely, 
Table 3. Comparison between FTD and AD

\begin{tabular}{|c|c|c|c|c|}
\hline & $p$ value & OR & $\begin{array}{l}\text { Lower } \\
(95 \% \mathrm{CI})\end{array}$ & $\begin{array}{l}\text { Upper } \\
(95 \% \mathrm{CI})\end{array}$ \\
\hline Anxiety $^{a}$ & 0.099 & 1.549 & 0.920 & 2.607 \\
\hline Depression $^{\mathrm{b}}$ & 0.828 & 0.924 & 0.453 & 1.883 \\
\hline Anxiety and & 0.161 & 1.538 & 0.842 & 2.806 \\
\hline depression $^{\mathrm{c}}$ & 0.439 & 0.734 & 0.335 & 1.608 \\
\hline \multicolumn{5}{|l|}{ Adjusted analysis ${ }^{\mathrm{d}}$} \\
\hline Anxiety & 0.146 & 1.592 & 0.851 & 2.979 \\
\hline Depression & 0.490 & 0.751 & 0.333 & 1.694 \\
\hline Age at participation in HUNT2 & 0.000 & 0.945 & 0.916 & .975 \\
\hline Gender & 0.801 & 1.074 & 0.617 & 1.868 \\
\hline Heart disease & 0.721 & 0.962 & 0.778 & 1.189 \\
\hline Diabetes & 0.371 & 0.509 & 0.116 & 2.232 \\
\hline Hypertension & 0.890 & 1.014 & 0.829 & 1.241 \\
\hline Metabolic disease & 0.615 & 0.958 & 0.809 & 1.133 \\
\hline Smoking & 0.585 & 1.099 & 0.782 & 1.545 \\
\hline Obesity & 0.670 & 0.967 & 0.828 & 1.129 \\
\hline
\end{tabular}

Anxiety and depression as risk factors for FTD compared with AD. CI, Confidence interval; OR, odds ratio. ${ }^{a}$ Anxiety entered as variable. ${ }^{b}$ Depression entered as variable. ${ }^{c}$ Anxiety and depression entered as variables. $\mathrm{d}$ Anxiety, depression, and confounders entered as variables.

Table 4. Comparison between $\mathrm{AD}$ and $\mathrm{CH}$ individuals

\begin{tabular}{|c|c|c|c|c|}
\hline & $p$ value & OR & $\begin{array}{l}\text { Lower } \\
(95 \% \text { CI) }\end{array}$ & $\begin{array}{l}\text { Upper } \\
(95 \% \text { CI) }\end{array}$ \\
\hline Anxiety $^{\mathrm{a}}$ & 0.003 & 2.778 & 1.404 & 5.498 \\
\hline Depression $^{\mathrm{b}}$ & 0.003 & 5.922 & 1.829 & 19.181 \\
\hline Anxiety and & 0.054 & 2.009 & 0.988 & 4.087 \\
\hline depression $^{c}$ & 0.016 & 4.389 & 1.311 & 14.690 \\
\hline \multicolumn{5}{|l|}{ Adjusted analysis ${ }^{\mathrm{d}}$} \\
\hline Anxiety & 0.114 & 1.967 & 0.850 & 4.554 \\
\hline Depression & 0.032 & 4.494 & 1.139 & 17.731 \\
\hline Age at participation in HUNT2 & 0.000 & 1.166 & 1.129 & 1.203 \\
\hline Gender & 0.029 & 0.559 & 0.332 & 0.943 \\
\hline Heart disease & 0.104 & 2.139 & 0.856 & 5.343 \\
\hline Diabetes & 0.379 & 2.005 & 0.426 & 9.430 \\
\hline Hypertension & 0.185 & 0.732 & 0.462 & 1.161 \\
\hline Metabolic disease & 0.161 & 0.972 & 0.934 & 1.011 \\
\hline Smoking & 0.222 & 1.247 & 0.875 & 1.778 \\
\hline Obesity & 0.160 & 1.412 & 0.872 & 2.287 \\
\hline
\end{tabular}

Anxiety and depression as risk factors for $\mathrm{AD}$ compared with $\mathrm{CH}$ individuals. CI, Confidence interval; OR, odds ratio. ${ }^{\mathrm{a}}$ Only anxiety entered as variable. ${ }^{\mathrm{b}}$ Only depression entered as variable. ${ }^{\mathrm{c}}$ Anxiety and depression entered as variables. ${ }^{d}$ Anxiety, depression, and confounders entered as variables.

depression was more likely to be reported at baseline in the HUNT2 study among those who later developed $\mathrm{AD}$ than in the $\mathrm{CH}$ control group. When FTD was compared with $\mathrm{AD}$, no significant increase in the risk of developing FTD was observed in patients who had reported anxiety or in patients who had reported depression. To our knowledge, no previous studies have eval- 
uated the association between both anxiety and depression together and the development of FTD. Thus, our finding that anxiety may be a risk factor for FTD needs further investigation.

Several studies have found depression to be a risk factor for AD [36-39] and for dementia in general [37, 40,41]. Numerous mechanisms for the association between depression and the development of dementia have been proposed, such as vascular disease, alterations in glucocorticoid steroids, hippocampal atrophy, increased depositions of $\beta$-amyloid plaques, inflammatory changes, and deficits of nerve growth factors or neurotrophins [42]. Depression has also been linked to habits like smoking, obesity, and reduced regular physical activity, which are also cardiovascular risk factors [43]. Another suggested shared mechanism is that of inflammation and immune activation, which can be characteristic of depression and is also associated with an increased risk for all types of dementia [43]. Depression as a risk factor for dementia has been better investigated in late-life depression (age over 60 years and older) [42]. The few studies investigating the association between early-life depression and dementia have consistently found depression as a risk factor for dementia and unlikely to be solely a prodrome of dementia [42].

In the unadjusted analyses in our study, we found a nearly significant association between anxiety and the later development of AD. A previous study has also found a similar association [44]. Other studies have found prior anxiety to be a risk factor for dementia in general, including $\mathrm{AD}[18,43-48]$. Few hypotheses have been offered to explain the association between anxiety and dementia. One suggestion is that apolipoprotein $\mathrm{E}$ may be linked to anxiety as well as dementia [49]. Other mechanisms suggest that neuropeptides and the hypothalamic-pituitary-adrenal axis could be involved [48]. Another possible mediating factor could be the use of benzodiazepines, which may be prescribed as treatment for anxiety. In some studies, benzodiazepine use has been found as a risk factor for AD [50], but it remains unclear if this association is more than merely correlative.

In our study, there were no significant associations for either anxiety or depression when FTD cases were compared with AD cases. This may have several explanations. The FTD group was significantly smaller than the AD group. It is also possible that some of the FTD cases had $\mathrm{AD}$, but with the type of neuropsychiatric symptoms seen in FTD. This is especially relevant for the FTD cases selected from the Nursing Home Dementia Register, which may have been in an advanced stage of AD at the time of formal dementia diagnosis. During the last stages of $\mathrm{AD}$, the neuropsychiatric symptoms seen in FTD may occur.

\section{Strengths and Limitations of the Study}

The main strength of our study is its longitudinal, population-based, nested case-control design. Another strength is the use of a validated dementia diagnosis and data on anxiety and depression from the HADS $[33,51]$. We were able to investigate risk factors measured in the HUNT2 years before the FTD and AD diagnoses were made. Furthermore, our study has a comparable number of FTD cases to other studies, where populations have varied from 61 to 129 cases [10-12, 14, 15, 29, 52, 53]. An exception was the study by Deutsch et al. [13] on head trauma as a risk factor for FTD, which had 1,016 FTD cases. A further advantage of our study was that in the multivariable analyses we were able to adjust for a large number of potential confounding factors.

There were also limitations to our study. Some of the dementia diagnoses in the Hospital Dementia Register were recorded retrospectively. Although most patients referred to hospitals were examined by multiple doctors who implemented standard routines, some files had missing data, which may have reduced the validity of some diagnoses [30]. The diagnosis of dementia in the Nursing Home Dementia Register was based on a review of data collected from patients, their family members, and their caregivers. However, two physicians with extensive clinical and research experience found the data sufficient to make a diagnosis 
according to established criteria. The number of patients diagnosed with FTD was higher in the Nursing Home Dementia Register. FTD patients may need treatment and nursing home care earlier than those with AD. Diagnosing dementia specifically as FTD in patients living in nursing homes is more difficult than in those attending hospital outpatient clinics, although the dataset from the Nursing Home Dementia Register included information on symptoms early in the course of the disease. Further, AD patients will develop a behavior and symptoms similar to FTD patients later in disease and are therefore often incorrectly diagnosed with FTD [30]. Consequently, a possible misclassification of dementia type may have affected the point estimates in our study because the FTD group may have consisted of both FTD and AD cases. Additionally, the $\mathrm{CH}$ control group comprised individuals with healthy brains and may not have been truly representative of the general population.

The HADS is self-rated and scoring could be biased by the person's feelings at the time they filled out the questionnaire. There is also a possibility that some FTD or AD cases developed cognitive impairment before participation in the HUNT2 study. Filling out a selfrated questionnaire may be problematic for individuals with cognitive impairment because insight and the ability to quantify emotional states may be impaired. Understanding and interpretation of the questions in the HADS may also be subject to individual variation. However, previous studies have shown the HADS to be satisfactory in terms of internal consistency, factor structure, and intercorrelation [51].

\section{Interpretation}

Our results suggest that we can view anxiety and depression as differing risk factors for FTD and AD. The finding that anxiety was more often reported in premorbid FTD than in AD can be explained by a shared underlying psychiatric component, for example, the suggested relationship between apolipoprotein E, anxiety, and dementia [49], or the use of medications, such as benzodiazepines [50]. However, we cannot rule out the possibility that the anxiety symptoms reported on the HADS at baseline in the HUNT2 study are part of a prodromal phase in FTD. The identification of early prodromal states in FTD continues to pose challenges [54]. Studies have found that it can take from 5 to 10 years to make a correct diagnosis $[55,56]$, and our findings warrant more research to further explain the correlation between anxiety and FTD.

Another important finding was that depression was more often reported in premorbid $\mathrm{AD}$ than in $\mathrm{CH}$ controls. This suggests that depression symptoms, as reported on the HADS at baseline in the HUNT2 study, may be part of a prodromal phase of AD. AD develops slowly and the prodromal phase has been estimated to last from 1 year to more than 10 years [57]. Furthermore, AD and depression may be linked by vascular disease, alterations in glucocorticoid steroids, hippocampal atrophy, increased depositions of $\beta$-amyloid plaques, inflammatory changes, and deficits of nerve growth factors or neurotrophins [42], none of which are commonly seen in FTD.

\section{Conclusion}

Our study results suggested that prior anxiety is associated with a diagnosis of FTD and prior depression is associated with $\mathrm{AD}$, after adjustment for other risk factors. Anxiety and depression as risk factors may play different roles in FTD and AD. Differences between FTD and AD in modifiable risk factors should be considered in future research, which requires a longitudinal design with long follow-up periods to clarify the consistency of earlier findings on modifiable FTD risk factors. Further research should also analyze genetic data to separate genetic and sporadic cases of FTD, providing further enlightenment of the possible relationships between modifiable and nonmodifiable risk factors for FTD. 
Rasmussen et al.: Anxiety and Depression as Risk Factors in FTD and AD

\section{Acknowledgements}

The Nord-Trøndelag Health Study (the HUNT study) is a collaboration between the HUNT Research Centre (Faculty of Medicine and Health Sciences, Norwegian University of Science and Technology [NTNU]), Nord-Trøndelag County Council, Central Norway Regional Health Authority, and the Norwegian Institute of Public Health. Special thanks go to the Department of Research, Nord-Trøndelag Hospital Trust, and academic librarian Ms. Linn Benjaminsen Hølvold at the medical library of Namsos Hospital, Nord-Trøndelag Hospital Trust.

\section{Statement of Ethics}

The study was conducted at the Namsos Hospital, Nord-Trøndelag Health Trust, with approval from the Regional Etisk Komite (REK), the Norwegian ethics committee. Participating patients gave written consent to take part in the HUNT2 and HUNT3 studies.

\section{Disclosure Statement}

The authors have no conflicts of interests to declare.

\section{References}

1 Alzheimer's Disease International. World Alzheimer Report 2015: The Global Impact of Dementia. An analysis of prevalence, incidence, costs and trends. London: Alzheimer`s Disease International; 2015.

2 Brookmeyer R, Johnson E, Ziegler-Graham K, Arrighi HM. Forecasting the global burden of Alzheimer's disease. Alzheimers Dement. 2007 Jul;3(3):186-91.

3 Kansal K, Mareddy M, Sloane KL, Minc AA, Rabins PV, McGready JB, et al. Survival in Frontotemporal Dementia Phenotypes: A Meta-Analysis. Dement Geriatr Cogn Disord. 2016;41(1-2):109-22.

4 Bott NT, Radke A, Stephens ML, Kramer JH. Frontotemporal dementia: diagnosis, deficits and management. Neurodegener Dis Manag. 2014;4(6):439-54.

5 Rosness TA, Engedal K, Chemali Z. Frontotemporal Dementia: An Updated Clinician's Guide. J Geriatr Psychiatry Neurol. 2016 Sep;29(5):271-80.

6 Mourik JC, Rosso SM, Niermeijer MF, Duivenvoorden HJ, Van Swieten JC, Tibben A. Frontotemporal dementia: behavioral symptoms and caregiver distress. Dement Geriatr Cogn Disord. 2004;18(3-4):299-306.

7 Bang J, Spina S, Miller BL. Frontotemporal dementia. Lancet. 2015 Oct;386(10004):1672-82.

8 Alzheimer's Association. 2013 Alzheimer's disease facts and figures. Alzheimers Dement. 2013 Mar;9(2):20845.

9 Neary D, Snowden J, Mann D. Frontotemporal dementia. Lancet Neurol. 2005 Nov;4(11):771-80.

10 Golimstok A, Cámpora N, Rojas JI, Fernandez MC, Elizondo C, Soriano E, et al. Cardiovascular risk factors and frontotemporal dementia: a case-control study. Transl Neurodegener. 2014 Jun;3(1):13.

11 Rosso SM, Landweer EJ, Houterman M, Donker Kaat L, van Duijn CM, van Swieten JC. Medical and environmental risk factors for sporadic frontotemporal dementia: a retrospective case-control study. J Neurol Neurosurg Psychiatry. 2003 Nov;74(11):1574-6.

12 Kalkonde YV, Jawaid A, Qureshi SU, Shirani P, Wheaton M, Pinto-Patarroyo GP, et al. Medical and environmental risk factors associated with frontotemporal dementia: a case-control study in a veteran population. Alzheimers Dement. 2012 May;8(3):204-10.

13 Deutsch MB, Mendez MF, Teng E. Interactions between traumatic brain injury and frontotemporal degeneration. Dement Geriatr Cogn Disord. 2015;39(3-4):143-53.

14 Borroni B, Alberici A, Agosti C, Premi E, Padovani A. Education plays a different role in Frontotemporal Dementia and Alzheimer's disease. Int J Geriatr Psychiatry. 2008 Aug;23(8):796-800.

15 Miller ZA, Rankin KP, Graff-Radford NR, Takada LT, Sturm VE, Cleveland CM, et al. TDP-43 frontotemporal lobar degeneration and autoimmune disease. J Neurol Neurosurg Psychiatry. 2013 Sep;84(9):956-62.

16 Onyike CU, Diehl-Schmid J. The epidemiology of frontotemporal dementia. Int Rev Psychiatry. 2013 Apr;25(2): 130-7.

17 International AsD, World Alzheimer Report 2015. The Global Impact of Dementia. An analysis of prevalence, incidence, costs and trends. London: International AsD; 2015. 
18 Burton C, Campbell P, Jordan K, Strauss V, Mallen C. The association of anxiety and depression with future dementia diagnosis: a case-control study in primary care. Fam Pract. 2013 Feb;30(1):25-30.

19 Povova J, Ambroz P, Bar M, Pavukova V, Sery O, Tomaskova H, et al. Epidemiological of and risk factors for Alzheimer's disease: a review. Biomed Pap Med Fac Univ Palacky Olomouc Czech Repub. 2012 Jun;156(2): 108-14.

20 Fratiglioni L, Winblad B, von Strauss E. Prevention of Alzheimer's disease and dementia. Major findings from the Kungsholmen Project. Physiol Behav. 2007 Sep;92(1-2):98-104.

21 Diniz BS, Butters MA, Albert SM, Dew MA, Reynolds CF 3rd. Late-life depression and risk of vascular dementia and Alzheimer's disease: systematic review and meta-analysis of community-based cohort studies. $\mathrm{Br}$ J Psychiatry. 2013 May;202(5):329-35.

22 da Silva J, Gonçalves-Pereira M, Xavier M, Mukaetova-Ladinska EB. Affective disorders and risk of developing dementia: systematic review. Br J Psychiatry. 2013 Mar;202(3):177-86.

23 Bandelow B, Michaelis S. Epidemiology of anxiety disorders in the 21st century. Dialogues Clin Neurosci. 2015 Sep;17(3):327-35.

24 Lépine JP, Briley M. The increasing burden of depression. Neuropsychiatr Dis Treat. 2011;7 Suppl 1:3-7.

25 Beckham EE, Leber WR. Handbook of depression. 2nd ed. New York: Guilford Press; 1995.

26 Stordal E, Bjartveit Krüger M, Dahl NH, Krüger Ø, Mykletun A, Dahl AA. Depression in relation to age and gender in the general population: the Nord-Trøndelag Health Study (HUNT). Acta Psychiatr Scand. 2001 Sep; 104(3):210-6.

27 Solhaug HI, Romuld EB, Romild U, Stordal E. Increased prevalence of depression in cohorts of the elderly: an 11-year follow-up in the general population - the HUNT study. Int Psychogeriatr. 2012 Jan;24(1):151-8.

28 Ramsawh HJ, Raffa SD, Edelen MO, Rende R, Keller MB. Anxiety in middle adulthood: effects of age and time on the 14-year course of panic disorder, social phobia and generalized anxiety disorder. Psychol Med. 2009 Apr;39(4):615-24.

29 Atkins ER, Bulsara MK, Panegyres PK. Cerebrovascular risk factors in early-onset dementia. J Neurol Neurosurg Psychiatry. 2012 Jun;83(6):666-7.

30 Bergh S, Holmen J, Gabin J, Stordal E, Fikseaunet A, Selbæk G, et al. Cohort profile: the Health and Memory Study (HMS): a dementia cohort linked to the HUNT study in Norway. Int J Epidemiol. 2014 Dec;43(6):175968.

31 Bosnes 0, Troland K, Torsheim T. A Confirmatory Factor Analytic Study of the Wechsler Memory Scale-III in an Elderly Norwegian Sample. Arch Clin Neuropsychol. 2016 Feb;31(1):12-7.

32 Krokstad S, Langhammer A, Hveem K, Holmen T, Midthjell K, Stene T, et al. Cohort Profile: the HUNT Study, Norway. Int J Epidemiol. 2013 Aug;42(4):968-77.

33 Snaith RP, Zigmond AS. The hospital anxiety and depression scale. Br Med J (Clin Res Ed).1986 Feb;292(6516): 344.

34 Bjelland I, Dahl AA, Haug TT, Neckelmann D. The validity of the Hospital Anxiety and Depression Scale. An updated literature review. J Psychosom Res. 2002 Feb;52(2):69-77.

35 Holmen J, Midthjell K, Krüger Ø, Langhammer A, Holmen TL, Bratberg GH, et al.; The Nord-Trøndelag Health Study 1995-97. (HUNT 2): objectives, contents, methods and participation. Nor Epidemiol. 2003;13:19-32.

36 Fuhrer R, Dufouil C, Dartigues JF; PAQUID Study. Exploring sex differences in the relationship between depressive symptoms and dementia incidence: prospective results from the PAQUID Study. J Am Geriatr Soc. 2003 Aug;51(8):1055-63.

37 Ownby RL, Crocco E, Acevedo A, John V, Loewenstein D. Depression and risk for Alzheimer disease: systematic review, meta-analysis, and metaregression analysis. Arch Gen Psychiatry. 2006 May;63(5):530-8.

38 Steenland K, Karnes C, Seals R, Carnevale C, Hermida A, Levey A. Late-life depression as a risk factor for mild cognitive impairment or Alzheimer's disease in 30 US Alzheimer's disease centers. J Alzheimers Dis. 2012; 31(2):265-75.

39 Barnes DE, Yaffe K, Byers AL, McCormick M, Schaefer C, Whitmer RA. Midlife vs late-life depressive symptoms and risk of dementia: differential effects for Alzheimer disease and vascular dementia. Arch Gen Psychiatry. 2012 May;69(5):493-8.

40 Baumgart M, Snyder HM, Carrillo MC, Fazio S, Kim H, Johns H. Summary of the evidence on modifiable risk factors for cognitive decline and dementia: A population-based perspective. Alzheimers Dement. 2015 Jun; 11(6):718-26.

41 Heser K, Wagner M, Wiese B, Prokein J, Ernst A, König HH, et al.; AgeCoDe Study Group. Associations between Dementia Outcomes and Depressive Symptoms, Leisure Activities, and Social Support. Dement Geriatr Cogn Disord Extra. 2014 Dec;4(3):481-93.

42 Byers AL, Yaffe K. Depression and risk of developing dementia. Nat Rev Neurol. 2011 May;7(6):323-31.

43 Zilkens RR, Bruce DG, Duke J, Spilsbury K, Semmens JB. Severe psychiatric disorders in mid-life and risk of dementia in late- life (age 65-84 years): a population based case-control study. Curr Alzheimer Res. 2014; 11(7):681-93

44 Wilson RS, Begeny CT, Boyle PA, Schneider JA, Bennett DA. Vulnerability to stress, anxiety, and development of dementia in old age. Am J Geriatr Psychiatry. 2011 Apr;19(4):327-34.

45 Skogen JC, Bergh S, Stewart R, Knudsen AK, Bjerkeset O. Midlife mental distress and risk for dementia up to 27 years later: the Nord-Trøndelag Health Study (HUNT) in linkage with a dementia registry in Norway. BMC Geriatr. 2015 Mar;15(1):23. 
46 Petkus AJ, Reynolds CA, Wetherell JL, Kremen WS, Pedersen NL, Gatz M. Anxiety is associated with increased risk of dementia in older Swedish twins. Alzheimers Dement. 2016 Apr;12(4):399-406.

47 Kassem AM, Ganguli M, Yaffe K, Hanlon JT, Lopez OL, Wilson JW, et al.; Osteoporotic Fractures in Men (MrOS) Study Research Group. Anxiety symptoms and risk of cognitive decline in older community-dwelling men. Int Psychogeriatr. 2017 Jul;29(7):1137-45.

48 Gallacher J, Bayer A, Fish M, Pickering J, Pedro S, Dunstan F, et al. Does anxiety affect risk of dementia? Findings from the Caerphilly Prospective Study. Psychosom Med. 2009 Jul;71(6):659-66.

49 Raber J. Role of apolipoprotein E in anxiety. Neural Plast. 2007;2007:91236.

50 Billioti de Gage S, Moride Y, Ducruet T, Kurth T, Verdoux H, Tournier M, et al. Benzodiazepine use and risk of Alzheimer's disease: case-control study. BMJ. 2014 Sep;349:g5205.

51 Mykletun A, Stordal E, Dahl AA. Hospital Anxiety and Depression (HAD) scale: factor structure, item analyses and internal consistency in a large population. Br J Psychiatry. 2001 Dec;179(6):540-4.

52 De Reuck JL, Deramecourt V, Cordonnier C, Leys D, Pasquier F, Maurage CA. Cerebrovascular lesions in patients with frontotemporal lobar degeneration: a neuropathological study. Neurodegener Dis. 2012;9(4):170-5.

53 Torralva T, Sposato LA, Riccio PM, Gleichgerrcht E, Roca M, Toledo JB, et al. Role of brain infarcts in behavioral variant frontotemporal dementia: Clinicopathological characterization in the National Alzheimer's Coordinating Center database. Neurobiol Aging. 2015 Oct;36(10):2861-8.

54 Welsh-Bohmer KA. Defining "prodromal" Alzheimer's disease, frontotemporal dementia, and Lewy body dementia: are we there yet? Neuropsychol Rev. 2008 Mar;18(1):70-2.

55 Rosness TA, Haugen PK, Passant U, Engedal K. Frontotemporal dementia: a clinically complex diagnosis. Int J Geriatr Psychiatry. 2008 Aug;23(8):837-42.

56 Rohrer JD, Nicholas JM, Cash DM, van Swieten J, Dopper E, Jiskoot L, et al. Presymptomatic cognitive and neuroanatomical changes in genetic frontotemporal dementia in the Genetic Frontotemporal dementia Initiative (GENFI) study: a cross-sectional analysis. Lancet Neurol. 2015 Mar;14(3):253-62.

57 Wilson RS, Leurgans SE, Boyle PA, Bennett DA. Cognitive decline in prodromal Alzheimer disease and mild cognitive impairment. Arch Neurol. 2011 Mar;68(3):351-6. 